\title{
Research on the Optimization of Emergency Reserve System for Natural Disasters in China
}

\author{
Shaoqing Geng*, Hanping Hou \\ Beijing Jiaotong University \\ School of Economics and Management \\ Beijing, China \\ 17120573@bjtu.edu.cn \\ Yue Wang \\ Assistant Engineer \\ Space star technology co., LTD \\ Beijing, China \\ Lixueb2141@163.com
}

\author{
$\mathrm{Na} \mathrm{Xu}$ \\ School of Economics and Management \\ Beijing University of Technology \\ Beijing, China \\ xingmeng82@126.com \\ Mingli Yu, Chenyang Zhao, Lu Huang \\ Beijing Jiaotong University \\ School of Economics and Management \\ Beijing, China \\ 17120573@bjtu.edu.cn
}

\begin{abstract}
China is one of the countries in the world which are most affected by natural disasters. In the face of natural disasters, emergency rescue after disasters must be scientific, fast and accurate. In order to fully improve the efficiency of emergency rescue, it is essential to optimize the emergency materials reserve system of natural disasters. According to the emergency materials storage system of natural disasters in China, there are government emergency supplies less, social emergency supplies reserve shortage, single reserve model, and low level of information. Through using qualitative research, putting forward to improve from three aspects of government, society and the degree of information.
\end{abstract}

Keywords-Natural disasters; Emergency supplies; Reserve optimization; Informaon degree

\section{INTRODUCTION}

In recent years, natural disasters such as earthquakes, tsunamis and typhoons in our country have occurred frequently. The features of them include multi types, wide area, high frequency and heavy loss. For example, the ice and snow disaster in the south in early 2008 and the 5.12 Wenchuan earthquake, the 2010 Yushu earthquake, the 2013 Ya'an earthquake, the 2013 "Haiyan" typhoon and others, these natural disasters have brought heavy losses to China's economic development, people's lives and property safety[1]. After the occurrence of natural disasters, relief supplies must be rapidly distributed to the affected areas, so as to reduce the impact of disasters and restore social stability of the affected areas.

The sudden and destructive nature of disasters and the time urgency of emergency supplies have posed more challenges to the emergency rescue after disasters. As a major part of effective emergency, relief supplies have important role in reducing casualties in disasters. In the event of a natural disaster, supplies must be sent to the scene in the shortest possible time [2]. The long-term and complicated rescue work can not solely rely on the emergency supplies that are stored by way of one side and should fully dispatches all parties' emergency supplies. Therefore, the imperfect reserve system for emergency supplies of natural disasters will seriously restrict the scientific and rational deployment of emergency relief supplies. Scholars' [3-7] study of emergency supplies systems make a contribution, but the construction of emergency supplies reserve system still remains a challenge. By adopting the method of qualitative research, researching and analyzing the emergency supplies of natural disasters, explore solutions, make full use of resources and improve the efficiency of emergency supplies.

\section{THE IMPORTANCE OF EMERGENCY SUPPLIES RESERVES OF NATURAL DISASTERS RESCUE}

The natural disaster refers to the natural phenomena that endangers or damages the living environment of human beings. The occurrence of most natural disasters is unpredictable, and its influence and scale increase with each passing day. Emergency supplies must be transported to place within 72 hours, otherwise it will seriously affect the efficiency of emergency rescue. In order to minimize the losses that are caused by natural disasters, emergency materials must meet the demand in the shortest possible time. Therefore, it is urgent to perfect the emergency rescue material system after a natural disaster.

The demand for emergency relief materials is large and involves a wide range. Sudden natural disasters require a large amount of emergency supplies, which are used to solve the problems of the wounded, epidemic prevention and health care after the disasters. If the emergency supplies can not be transported in a timely manner, the bad influence of the natural disasters will be further expanded, and eventually may turn them into worse disasters. In this way, the losses of disasters will develop in depth, and the consequences will be unimaginable. 


\section{PROBLEMS OF NATURAL DISASTER EMERGENCY SUPPLIES RESERVE SYSTEM IN CHINA}

\section{A. Reserve amount of government emergency supplies is insufficient}

At present, China has formed a national, provincial and county level of government and more emergency supplies reserve system. Government emergency supplies reserve system is a major source of natural disaster emergency relief supplies, but the government reserves a small amount of emergency supplies, there is a short board organizational level. For example, after the Wenchuan earthquake in 2008, 150,000 tents were urgently dispatched to 10 material reserves stores from surrounding cities such as Wuhan and Nanning, still not meeting the demand for tents in disaster-stricken areas. There was a huge gap. And many county-level governments dose not conduct emergency supplies reserve, leading to a larger gap [8]

National reserve emergency rescue supplies are few, mostly clothing, tents and so on, which cause natural disasters, relief supplies and daily necessities supply are insufficient. The distribution of emergency materials are in different departments and inefficient departments increase the difficulty of emergency material management after natural disasters. The emergency material support capability can not be fully tapped.

\section{B. Social natural disasters emergency supplies are inadequate}

In our country, after the natural disaster, the emergency rescue mainly depends on the government, ignoring the social groups, enterprises, families and other social reserve forces. Social rescue has not been fully utilized [9-11].

In China, non-governmental organizations such as charitable organizations, the Red Cross and the Logistics Association should play important roles to the government's relief supplies, but the type and quantity of their stock can far not meet the actual needs. And most enterprises put profit as their goal, but not for their own risk reserves, unable to save themselves after the disaster, it is difficult to achieve rapid rescue, leading to miss the best time to rescue. In the natural disasters, the family is the victim and the recipient, self-help and mutual aid seem particularly important, but people are lack of the knowledge of the family emergency supplies reserve, the lack of basic materials and tools. Household reserve is almost blank.

\section{Natural disaster emergency supplies reserve mode is single}

Most of China's emergency supplies are stored in physical form in warehouses, and are called immediately after natural disasters [12]. However, the form of a single, agreement reserves such as contract reserves and productivity reserves accounted for relatively small [13]. The contract reserve is a form that calls for goods after a natural disaster by contracting with the government departments, units, social groups and other organizations that already have supplies. Productivity reserve means that after a natural disaster, the enterprise that produces emergency supplies can quickly convert the productive forces to meet the demand.
At present, the low utilization rate of these two forms in our country leads to the difficulty of sharing emergency supplies between governments and enterprises, increases the cost of material reserves and reduces the resource utilization rate.

\section{The information sharing of natural disaster emergency supplies reserve is at a low degree}

At present in our country, the government and enterprises, between none government organizations and other emergency supplies supply, more difficult to master reserve emergency supplies production, distribution, quantity and type of specific information, has not yet formed a complete integrated management platform. Information level of natural disaster emergency supplies is not high, which will seriously influence the natural disaster emergency supplies reserve system management efficiency. Especially after the occurrence of huge natural disasters, it is difficult to obtain complete reserve information, which brings obstacles to the effective supply of emergency supplies and leads to 'blind spots'.

\section{MEASURES TO IMPROVE NATURAL DISASTER EMERGENCY SUPPLIES RESERVE SYSTEM}

\section{A. Improve the system of emergency supplies of land reserve}

Based on the demand for emergency supplies, the number and the type of emergency supplies for natural disasters should be increased to ensure that the affected people can receive initial relief within 12 hours of natural disasters for rapid rescue.

All local governments should also give full consideration to the local characteristics and set up the Emergency Materials Reserve Center in the disaster-stricken areas so as to ensure the targeted and rapid transfer of materials [14-15]. Based on the national laws, normative documents and the characteristics of the local area, a natural disaster emergency rescue plan and system is established in line with its own conditions. In accordance with the degree of natural disasters and the scope of endangering their grading, considering the possible natural disasters, determine the main tasks of each department and the relationship between various departments, and make the appropriate emergency supplies reserve. Through the emergency supplies reserve information system to ensure the rapid supply of emergency supplies post-disaster and improve the overall responsiveness.

\section{B. Strengthen the construction of social emergency supplies reserve system}

After the natural disaster occurring, in addition to the government reserve, it is also necessary to consider the reserve of public emergency supplies such as social organizations, enterprises and families [16], fully mobilize the enthusiasm of all parties, make common reserve for emergency supplies of natural disasters, make up for the shortage of emergency relief supplies to achieve the government as the leading and fully coordinate the use of social resources to ensure rapid and unimpeachable emergency rescue.

In order to play a market role, integrating the market consolidation of goods through the government and enterprises 
signing a contract or agreement, the market circulation of materials can be included in natural disaster emergency supplies reserve system after the occurrence of natural disasters, the government may make a call to ensure the supply of emergency supplies while reserving production capacity for the production of relief supplies. The government can use a variety of ways to provide the necessary compensation to the enterprises that provide the emergency relief materials. Enterprises should also, according to their own circumstances, reserve supplies and means of production, especially the circulation of the reserve market is small, and in the event of an accident, their own very much needed supplies.

Encouraging families to reserve emergency supplies and raising public awareness of the importance of emergency supplies for their families are necessary. Emergency supplies should meet short-term needs, such as medicines, compressed cookies, water and escape ropes. All these can help families survive natural disasters self-help and mutual aid. Fully mobilize social forces such as social organizations, enterprises and families, establish social mobilization mechanisms and incentive mechanisms, and establish a public emergency material reserve system [17].

\section{Optimize emergency supplies reserve mode}

Increase the contract reserve and production capacity reserve and other reserve ways, choose the industry with high credibility and comprehensive strength, and sign an agreement to clarify the rights and obligations of the parties. After the occurrence of natural disasters, the relevant enterprises produce emergency materials according to the requirements, and ensure the supply of emergency supplies. The government should update the agreement according to the actual operation of the enterprise.

The appropriate reserve model for emergency materials with different properties, especially for the shelf life time is short, it is difficult to preserve food and can take the contract reserves and production capacity reserve etc., for example, aid of drugs and vaccines should adopt the productivity reserve mode.

\section{Enhance the degree of information of emergency supplies for natural disasters}

The construction of a comprehensive information management for emergency relief supplies of natural disaster emergency supplies information platform, requires multiple sectors linkage, coordination and cooperation between regions [18]. This platform which is used for emergency rescue supplies can announce real-time dynamic reserve information supply, carry on the emergency rescue statistics, material classification, and updated distribution. Helps to effectively carry out emergency rescue work after the disaster, to a certain extent, to prevent further disasters too large, reduce the loss of natural disasters. At the same time, the public can also strengthen the supervision of emergency supplies reserves.

Through the open, efficient and modern emergency material reserve management platform, emergency material management department can grasp the specific circumstances of emergency materials that are stored by government, enterprises and social organizations, and grasp the update of emergency materials in real time. It is beneficial to realize effective command and manage emergency relief materials, and avoid unnecessary waste and the loss of resources.

\section{CONCLUSION}

For the sudden and frequent natural disasters, emergency supplies reserves are put forward higher requirements, through the research, the present situation of emergency rescue supplies reserve in our country is inadequate, reserves and transport area dispersion capacity is limited, which makes our existing emergency materials reserve system a serious problem. According to the natural disasters emergency material reserves, less social natural disaster emergency supplies reserve shortage, single natural disaster emergency supplies reserve mode and natural disaster emergency supplies reserve information sharing at a low level, bring forward strategies that polish up China's natural disaster emergency material reserve system: improve the reserve system, strengthen the construction of social territorial emergency supplies reserve system, optimize natural disaster emergency supplies reserve mode and strengthen the natural disaster emergency information materials Optimize the reserve system of emergency materials, allocate emergency resources effectively, strive for the maximum social benefits with the minimum input, and greatly reduce casualties and property losses.

\section{REFERENCES}

[1] Wei Wang. Analysis of Typical Structure of Snow, Snow and Earthquake Disasters and Research on Disaster Mitigation Measures [D]. Xi'an University of Architecture and Technology, 2010

[2] Xueying Gao. Large-scale emergency rescue resources layout and scheduling optimization method [D]. Jilin University, 2012.

[3] Yixian Chen. Disaster emergency supplies demand forecasting and reserve management research [D]. Chongqing University of Posts and Telecommunications, 2016.

[4] Li Yang. China's emergency supplies reserve based on resource allocation [D]. Fuzhou University, 2014.

[5] Whybark D. Issues in managing disaster relief inventories [J]. International Journal of Production Economics, 2007, 108 (1-2): 228235.

[6] Roni M S, Jin M, Eksioglu S D. A hybrid inventory management system responding to regular demand and surge demand [J]. Omega, 2015, 52: 190-200.

[7] Yi W, Özdamarb L. A dynamic logistics coordination model for evacuation and support in disaster response activities[J]. European Journal of Operational Research, 2007, 179(3):1177-1193.

[8] Jialin Nie, Qiong Hong. On natural disaster emergency logistics management system construction [J]. Logistics Science and Technology, 2013,36 (12): 32-35.

[9] Xin Ma, Tao Chen, Jun Huang. Many important issues in establishing a system of emergency supplies for whole society $[\mathrm{J}]$.Engineering Research-Engineering in the Interdisciplinary Perspective, 2011,3 (01): $82-86$

[10] Tao Chen, Jun Huang, Ling Zhang. Study on the coordination of the physical reserve and the reserve model of production capacity of the agreement [J]. China management science, 2013,21 (05): 149-156.

[11] Jiaxiang Zhao. National emergency supplies reserve layout and agreement enterprise reserve mode [D]. Southwest Jiaotong University, 2015 .

[12] Huiqin Hu. Refined grain [D]. coordination mechanism of emergency storage system of China Agricultural University, 2014. 
[13] Xiaochun Yang.Study on the Construction of Logistics Information System Based on Emergency Logistics [J] .Electronic Business, 2017, (06): 5-6.

[14] Jianliang Yang, Hanping Hou. Study on rapid rescue of emergency logistics based on natural disaster [J]. logistics technology, 2016,35 (12): 10-13.

[15] Yongling Zhang. Research on Emergency Material Storage Based on AHP [J]. Acta Metallurgica Sinica, 2011,26 (03): 120-125.

[16] Jianliang Yang, Hanping Hou. Journal of Beijing Jiaotong University (Social Sciences Edition), 2017,16 (04): 72-79 Comment for this article:
Feedback Author Email Title Code Content Copyright by Journal of Beijing Jiaotong University.

[17] Yuyi Zhang, Cunzhang Zhou, Guiqiang Wang. Organization and command of emergency logistics for major natural disasters [J]. logistics technology, 2009,28 (08): 18-19.

[18] Brenda D. Phillips, William C. Metz, Leslie A. Nieves. Disaster threat: Preparedness and potential response of the lowest income quartile[J]. Global Environmental Change Part B Environmental Hazards, 2005, 6(3):123-133 